\title{
PRESENTATION, TREATMENT AND OUTCOMES OF ACUTE CORONARY SYNDROME IN A TERTIARY CARE HOSPITAL IN CENTRAL NEPAL
}

\author{
Barakoti MP ${ }^{1}$, Regmi $\mathrm{SR}^{2}$, Dhital $\mathrm{BM}^{3}$
}

\begin{abstract}
INTRODUCTION: Nepal is facing with increasing rate of coronary artery disease, yet little is known about presentation, treatment and outcome of this disease in our population and our setting. We aimed to document the characteristics in consecutive cases in a tertiary level hospital.
\end{abstract}

MATERIAL AND METHODS: Seventy eight total cases were documented in six months period and evaluated the data on presentation, management, in-hospital mortality and non-fatal adverse cardiovascular event (MACE).

RESULTS: Mean (SD) age at presentation was 65 (13) years and did not differ among acute coronary syndrome (ACS) types $(\mathrm{STEMI}=23 \%$, Non ST Elevation Myocardial Infarction $(\mathrm{NSTEMI})=28 \%, \mathrm{UA}=49 \%)$. ACS is still a disease prevalent in $>50$ years of age $(88 \%)$. Dual antiplatelet agents and statin were used $>90 \%$ cases and coronary angiography was performed in $\sim 50 \%$ cases. Unstable angina patients has significantly higher number of normal coronaries or noncritical stenosis. Percutaneous coronary intervention rates were significantly higher among STEMI admissions ( $38 \%$ vs $22 \%$ vs $13 \%, \mathrm{P}=0.003)$. Unadjusted in-hospital mortality rate was $11 \%$, significantly higher than NSTEMI (5\%) and UA $(5 \%)$. Non-fatal major MACE rate including reinfarction, heart failure or cardiogenic shock was also high in STEMI and NSTEMI patients than in unstable angina patients.

CONCLUSION: This study represents contemporary practice of ACS care and provides opportunity to improve care for symptom recognition, treatment options and medical therapy.

KEY WORDS: Acute coronary syndrome, Outcomes

1. Associate Professor, Department of Cardiology, Chitwan Medical College Teaching Hospital, Bharatpur, Chitwan, Nepal

2. Professor, Department of Cardiology, Chitwan Medical College Teaching Hospital, Bharatpur, Chitwan, Nepal

3. Assistant Professor, Department of Cardiology, Chitwan Medical College Teaching Hospital, Bharatpur, Chitwan, Nepal

For Correspondence

Dr. Murari Prasad Barakoti

Associate Professor,

Department of Cardiology,

Chitwan Medical College, Bharatpur, Chitwan, Nepal.

E-mail:drmuraribarakoti@gmail.com 


\section{INTRODUCTION}

Cardiovascular disease (CVD) is the leading cause of death throughout the world including developing countries. Coronary artery disease is the major reason for CVD. The constellation of symptoms compatible with acute myocardial ischemia is termed as acute coronary syndrome whether actual infarction has occurred or not. The syndrome encompasses ST segment elevation myocardial infarction, non-ST segment myocardial infarction and unstable angina.

Cardiovascular diseases are increasing in an overwhelming fashion in the developing nations. Between 1990 and 2020, the disease is estimated to increase by $137 \%$ in men and $120 \%$ in women in these countries, compared to $30-60 \%$ increase in the developed countries. ${ }^{1}$ Furthermore, South Asians are have a high prevalence of risk factors, and they have earlier age of onset and more people suffer from STEMI. ${ }^{2}$ Most data in patients with acute coronary syndrome are from large registries from middle-income and high-income countries. Three largest registries in India till date are; OASIS 2 (1028 patients 1990- 2000) ${ }^{3}$, CREATE (20937 patients, 2001 to 2005) ${ }^{4}$ and Kerala ACS registry (25748 patients, 2007 to $2009)^{5}$. We aimed to document the clinical characteristics, treatment and in-hospital outcome of ACS patients who were admitted to a tertiary care hospital in central Nepal.

\section{MATERIALAND METHODS}

Based on local expert input, there are more than 15 acute care hospital in Chitwan district but currently only two teaching hospitals are capable of providing primary percuataneous coronary intervention (PCI) facility to people with acute coronary syndrome. CMC teaching hospital is one of them. We collected 78 consecutive cases of acute coronary syndrome admitted in coronary care unit of CMC teaching hospital from Kartik 2070 to Chaitra 2070 for the period of 6 months. Standard guidelines and hospital practice was used to diagnose and manage the cases according to the individual situation. Ethical clearance was taken from the institutional board. The investigators abstracted the in-hospital data regarding patient demographics, vital signs, diagnostics, treatment and outcomes from the medical record. Continuous variables are presented in mean (standard deviations) and categorical variables are as proportions. Comparison by ACS type were made via analysis of variance for continuous variables and chi square test for categorical variables. A two- sided $\mathrm{P}$ value $<0.005$ defined statistical significance. We used IBM SPSS v. 20 for our analysis.

\section{RESULTS}

Demographics, medical history and clinical presentation The mean age of patients was 65.79 (13.19) years and about half of them were men. ACS is prevalent in age more than 50 years, only $12 \%$ patients were below 50 years of age. Unstable angina was the predominant type. Risk factors prevalence including history of diabetes, hypertension, current or past smoking, documented past myocardial infarction or history of dyslipidemia were similar across ACS types and majority of patients presented after 24 hours of onset of chest pain. Fifteen percent participants were presented with Killip class $>1$ and blood glucose and serum creatinine $>2 \mathrm{mg} / \mathrm{dl}$ were similar in all three presentation of ACS.

Table 1: Patient characteristics on presentation by acute coronary syndrome type

\begin{tabular}{|c|c|c|c|c|c|}
\hline & \begin{tabular}{|l} 
STEMI \\
$(\mathrm{N}=18)$
\end{tabular} & \begin{tabular}{|l} 
NSTEMI \\
$(\mathrm{N}=22)$
\end{tabular} & \begin{tabular}{|l|}
$\mathrm{UA}$ \\
$(\mathrm{N}=38)$
\end{tabular} & $\begin{array}{l}\text { Total } \\
(\mathrm{N}=78)\end{array}$ & Pvalue \\
\hline Percentage & $23 \%$ & $28 \%$ & $49 \%$ & $100 \%$ & \\
\hline Sex (male), $N(\%)$ & $9(50)$ & $13(59 \%)$ & $16(42)$ & $38(48)$ & 0.444 \\
\hline Age, years (SD) & \begin{tabular}{|l|}
$62.83(13.19)$ \\
\end{tabular} & \begin{tabular}{|l}
$71.82(10.63)$ \\
\end{tabular} & \begin{tabular}{|l|}
$63.71(12.80)$ \\
\end{tabular} & \begin{tabular}{|l|l|}
$65.79(13.19)$ \\
\end{tabular} & 0.038 \\
\hline $\begin{array}{l}\text { Age strata } \\
<50 \text { years, } \mathrm{N}(\%) \\
50-70 \text { years, } \mathrm{N}(\%) \\
>70 \text { years, } \mathrm{N}(\%) \\
\end{array}$ & $\begin{array}{l}3(17) \\
9(50) \\
6(33) \\
\end{array}$ & $\begin{array}{l}0(0) \\
10(45) \\
12(55) \\
\end{array}$ & \begin{tabular}{|l}
$6(16)$ \\
$20(53)$ \\
$12(31)$ \\
\end{tabular} & $\begin{array}{l}9(12) \\
39(50) \\
30(38) \\
\end{array}$ & 0.218 \\
\hline $\begin{array}{l}\text { Key risk factors } \\
\text { History of diabetes, } \mathrm{N}(\%) \\
\text { History of hypertension, } \mathrm{N}(\%) \\
\text { History of current smoking, } \mathrm{N}(\%) \\
\text { History of past smoking, } \mathrm{N}(\%) \\
\text { History of past MI, } \mathrm{N}(\%) \\
\text { History of dyslipidemia, } \mathrm{N}(\%) \\
\end{array}$ & $\begin{array}{l}4(22) \\
7(39) \\
6(33) \\
4(22) \\
0(0) \\
2(11) \\
\end{array}$ & $\begin{array}{l}5(23) \\
10(46) \\
7(32) \\
6(27) \\
2(10) \\
1(5) \\
\end{array}$ & $\begin{array}{l}11(29) \\
18(47) \\
8(21) \\
11(29) \\
2(5) \\
2(5) \\
\end{array}$ & $\begin{array}{l}20(26) \\
35(45) \\
21(27) \\
21(27) \\
4(5) \\
5(6) \\
\end{array}$ & $\begin{array}{l}0.808 \\
0.836 \\
0.520 \\
0.789 \\
0.431 \\
0.165 \\
\end{array}$ \\
\hline $\begin{array}{l}\text { Clinical features on presentation } \\
\text { Symptom onset to hospital } \\
\text { presentation } \\
<4 \text { hours, } \mathrm{N}(\%) \\
4-12 \text { hours, } \mathrm{N}(\%) \\
12-24 \text { hours, } \mathrm{N}(\%) \\
>24 \text { hours, } \mathrm{N}(\%) \\
\end{array}$ & $\begin{array}{l}2(11) \\
2(11) \\
2(11) \\
12(67) \\
\end{array}$ & $\begin{array}{l}4(18) \\
3(17) \\
7(39) \\
8(44) \\
\end{array}$ & $\begin{array}{l}3(8) \\
2(5) \\
11(29) \\
22(58) \\
\end{array}$ & $\begin{array}{l}9(11) \\
7(9) \\
20(26) \\
42(54) \\
\end{array}$ & 0.383 \\
\hline Heart rate, mean (SD) & \begin{tabular}{|l|}
$93.44(18.14)$ \\
\end{tabular} & $86.45(22.30)$ & $85.45(23.40)$ & $87.58(21.58)$ & 0.433 \\
\hline Systolic BP (mmHg), mean (SD) & $123(38)$ & $131(25)$ & $138(24)$ & $132(28)$ & 0.191 \\
\hline Diastolic BP (mmHg), mean (SD) & $78(12)$ & $85(18)$ & $85(17)$ & $83(16)$ & 0.372 \\
\hline Killip class $>1, \mathrm{~N}(\%)$ & $3(17)$ & $4(18)$ & $5(13)$ & $12(15)$ & 0.861 \\
\hline Creatinine $>2 \mathrm{mg} / \mathrm{dl}, \mathrm{N}(\%)$ & $2(11)$ & $5(23)$ & $5(13)$ & $12(15)$ & 0.467 \\
\hline Positive cardiac enzyme, $\mathrm{N}(\%)$ & $6(33)$ & $12(55)$ & $0(0)$ & $18(23)$ & 0.001 \\
\hline Blood glucose (mg/dl), mean (SD) & $134(61)$ & $147(74)$ & $150(65)$ & $146(66)$ & 0.729 \\
\hline
\end{tabular}

\section{In-hospital diagnostics and management}

Coronary angiography was performed in $\sim 50 \%$ of all patients with no statistical difference across ACS types (Table 2). Thrombolysis was performed in $16 \%$ of STEMI patients and none in NSTEMI \& UA patients. Normal coronary arteries were more common in unstable angina group than in STEMI or NSTEMI. Single vessel disease is more common in 
NSTEMI and those with STEMI are more likely to have double or triple vessel disease. One case of unstable angina presented with left main stenosis which was referred to another center for coronary artery bypass surgery. Forty percent of STEMI patients underwent PCI as compared to $22 \%$ and $13 \%$ of NSTEMI and unstable angina respectively $(\mathrm{P}=0.003)$. Use of dual-antiplatelet drug and statin was $>90 \%$ in all ACS types and beta blockers were used in $65 \%$ of all cases. Some form of heparin was given in $68 \%$ of all cases without any statistical difference across ACS types. Temporary pacemaker insertion was needed in $22 \%$ of STEMI patients all of whom had inferior wall MI with complete heart block.

Table 2: In-hospital management, by acute coronary syndrome type

\begin{tabular}{|l|l|l|l|l|l|}
\hline & $\begin{array}{l}\text { STEMI } \\
(\mathbf{N}=18)\end{array}$ & $\begin{array}{l}\text { NSTEMI } \\
(\mathbf{N}=\mathbf{2 2})\end{array}$ & $\begin{array}{l}\text { UA } \\
\mathbf{( N = 3 8 )}\end{array}$ & $\begin{array}{l}\text { Total } \\
(\mathbf{N = 7 8 )}\end{array}$ & P value \\
\hline Coronary angiography, N (\%) & $11(61)$ & $9(41)$ & $20(52)$ & $40(51)$ & 0.152 \\
Normal coronaries, N (\%) & $3(27)$ & $2(22)$ & $12(60)$ & $17(42)$ & 0.001 \\
Non-critical stenosis, N (\%) & $0(0)$ & $0(0)$ & $1(5)$ & $1(2)$ & $<0.001$ \\
Single vessel disease, N (\%) & $5(45)$ & $7(78)$ & $4(20)$ & $16(40)$ & $<0.001$ \\
Double vessel disease, N (\%) & $2(18)$ & $0(0)$ & $2(10)$ & $4(10)$ & $<0.001$ \\
Triple vessel disease, N (\%) & $1(9)$ & $0(0)$ & $0(0)$ & $1(2)$ & $<0.001$ \\
Left main disease, N (\%) & $0(0)$ & $0(0)$ & $1(5)$ & $1(2)$ & \\
\hline In-patient medical therapy & & & & & \\
Aspirin, N (\%) & $17(95)$ & $22(100)$ & $36(95)$ & $75(96)$ & 0.541 \\
Clopidogrel, N (\%) & $17(95)$ & $20(91)$ & $34(89)$ & $71(91)$ & 0.831 \\
Beta-blockers, N (\%) & $14(77)$ & $12(55)$ & $25(65)$ & $51(65)$ & 0.338 \\
Statin, N (\%) & $17(95)$ & $21(95)$ & $35(92)$ & $73(94)$ & 0.551 \\
ACE-inhibitor/ARB, N (\%) & $14(77)$ & $16(72)$ & $34(89)$ & $64(82)$ & 0.215 \\
Nitrate, N (\%) & $14(77)$ & $21(95)$ & $34(89)$ & $69(88)$ & 0.962 \\
Calcium channel blocker, N (\%) & $1(6)$ & $1(5)$ & $4(11)$ & $6(8)$ & 0.645 \\
Any heparin, N (\%) & $14(77)$ & $15(69)$ & $24(63)$ & $53(68)$ & 0.106 \\
\hline Percutaneous coronary intervention, N (\%) & $7(38)$ & $5(22)$ & $5(13)$ & $17(21)$ & 0.003 \\
\hline Referral for CABG, N (\%) & $0(0)$ & $0(0)$ & $1(3)$ & $1(1)$ & 0.008 \\
\hline Temporary pacemaker insertion, N (\%) & $4(22)$ & $0(0)$ & $0(0)$ & $4(5)$ & 0.003 \\
\hline
\end{tabular}

\section{In-hospital outcome}

The unadjusted in-hospital mortality rate was $11 \%$ in STEMI patients, compared with substantially lower mortality in NSTEMI and UA patients ( $5 \%$ each). Non-fatal major adverse cardiovascular event such as reinfarction, heart failure, or cardiogenic shock were also common in STEMI and NSTEMI patients compared to unstable angina.

Table 3: In-hospital event rate, by acute coronary syndrome type

\begin{tabular}{|l|l|l|l|l|l|}
\hline & $\begin{array}{l}\text { STEMI } \\
(\mathrm{N}=18)\end{array}$ & $\begin{array}{l}\text { NSTEMI } \\
(\mathrm{N}=22)\end{array}$ & $\begin{array}{l}\text { UA } \\
(\mathrm{N}=38)\end{array}$ & $\begin{array}{l}\text { Total } \\
(\mathrm{N}=78)\end{array}$ & Pvalue \\
\hline Unadjusted death, $\mathrm{N}(\%)$ & $2(11)$ & $1(5)$ & $2(5)$ & $5(6)$ & 0.001 \\
\hline Reinfarction, $\mathrm{N}(\%)$ & $1(6)$ & $1(5)$ & $1(2)$ & $3(4)$ & 0.096 \\
\hline Heart failure or cardogenic shock, $\mathrm{N}(\%)$ & $2(11)$ & $2(9)$ & $0(0)$ & $4(5)$ & 0.001 \\
\hline $\begin{array}{l}\text { Death, reinfarction, heart failure or } \\
\text { cardiogenic shock, } \mathrm{N}(\%)\end{array}$ & $5(27)$ & $4(18)$ & $3(8)$ & $12(15)$ & 0.003 \\
\hline
\end{tabular}

\section{DISCUSSION}

We analyzed data from a single tertiary level hospital in central Nepal with acute coronary syndromes. Despite being single center study, short duration of observation and data collected in coronary care units due to logistic considerations, it provides contemporary care pattern in our actual situation and provides a lot for quality improvement. By contrast with data from Indian registries ${ }^{3-5}$, unstable angina was more common presentation type. People more aware of the situation and threshold for diagnosis was lower among physicians nowadays based on symptoms and risk factors analysis. There is no diagnostic single test for it, however, and diagnosis depends on physician discretion.

Patient level variable such as recognition of symptom and delayed symptom to door time were associated with increased risk of mortality and MACE. This has opportunity for increased public awareness to seek emergency care in the setting of symptoms consistent with ACS. There is need of education both side of the coin: some patients being extracautious for every symptoms and some patients not understanding the gravity of the situation.

Age and age distributions were similar to prior registries conducted in India, Europe and United States. Unstable angina was more prevalent in females than in males, and Non-ST elevation MI common in males but overall presentation was balanced. Smoking in the past or present is most common risk factor associated present in more than $50 \%$ of cases of acute coronary syndrome signifying the role and need to understand by the public. Overall one-fourth of patients were diabetic and hypertension was present in $45 \%$ of ACS and there was no differences between types of ACS for risk factors presence. These findings were similar to Indian registries CREATE ${ }^{4}$ and ACS Kerala ${ }^{5}$ registry.

Coronary angiography was performed in about $50 \%$ cases overall, more in STEMI group and also in unstable angina group. However many unstable angina patients had normal coronaries or not-critical stenosis. This suggests that diagnosis of unstable as a clinical judgment may only be safely proved or refuted by timely coronary angiography. Multi-vessel disease are more frequent in STEMI group. STEMI patients are more likely to be treated with coronary angioplasty and stenting $(\mathrm{P}=$ $0.003)$. This is also similar results as from ACS Kerala registry 
and CREATE registry. Angioplasty rate was higher in our study ( 21 percent) than these registry data because we give option of coronary angiography in most patients whereas these registry data were collected from a number of hospital in which only $22 \%$ hospitals had cardiac catheterization facilities in ACS Kerala registry (12\%) and 52\% hospital in CREATE registry $(7.5 \%)$. One of the reason for this is very low rate of coronary intervention in poor socioeconomic class $(2 \%)$ in CREATE registry.In-hospital mortality was more common in STEMI group and overall mortality in ACS was $6 \%$. This was slightly higher than ACS Kerala registry and similar to CREATE registry. As expected, a composite of death, reinfarction, heart failure or cardiogenic shock, was more common in STEMI group compared to NSTEMI and UA.

Our study has several limitations. The data collected are observational and single center data which has facility of cardiac catheterization. So it doesn't truly reflect the real picture of ACS care in Nepal. Thirdly patient data were collected in the coronary care unit due to logistical considerations, which may have led to underestimate in event rate, since patients who died in the casualty ward would not have been included in the analysis. Fourth, we did not measure the socioeconomic condition of the participants which have strong consideration for the management plan of ACS. Percutaneous coronary intervention is more effective but costly procedure which many people cannot afford at the immediate time period. More to it, we did not capture the follow-up data to look for post-discharge event rate, adherence to medication and lifestyle recommendations.

\section{CONCLUSION}

These data represent contemporary practice of ACS care in one of tertiary level hospital in Nepal. This demonstrate opportunity for improving quality of care in ACS and there is much needed effort to educate people for recognize symptoms of ACS and seek emergency care, to provide quality care by experts and to provide the medical therapy and life style changes that can decrease mortality and MACE and prolong life. Overall health care should be improved along with improvement in socioeconomic status of people.

\section{REFERENCES}

1. YusufS, Reddy KS, Singhi M. Global burden of cardiovascular disease: Part II: variations in cardiovascular disease by specific ethnic groups and geographic regions and prevention strategies. Circulation 2001;104: 2855-64. http://dx.doi.org/10.1161/hc4701.099488 PMid:11733407

2. Joshi P, Islam S, Pais P, et al. Risk factors for early myocardial infarction in South Asians compared with individuals in other countries. JAMA 2007; 297: 286-94. http://dx.doi.org/10.1001/jama.297.3.286 PMid:17227980

3. Prabhakaran D, YusufS, Mehta S, Pogue J, Avezum A, Budaj A, et al. Two-year outcomes in patients admitted with non-ST elevation acute coronary syndrome: results of the OASIS registry 1 and 2. Indian Heart J 2005; 57:217-225. PMid:16196178

4. Xavier D, Pais P, Devereaux PJ, Xie C, Prabhakaran D, Reddy $K S$ et al. Treatment and outcomes of acute coronarysyndromes in India (CREATE): a prospective analysis of registry data. Lancet2008;371:1435-1442 http://dx.doi.org/10.1016/S0140-6736(08)60623-6

5. Mohanan PP, Mathew R, Harikrishnan S, Krishnan MN, Zachariah $G$, Joseph $J$, et al. on behalf of the Kerala ACS Registry Investigators. Presentation, management, and outcomes of 25748 acute coronary syndrome admissions in Kerala, India: results from the Kerala ACS Registry. Eur Heart J2012; : ehs219v1-ehs219. 